\title{
Smart working in the COVID-19 emergency: a comparative study of the banking and insurance sectors
}

\author{
Eleonora Veglianti, ${ }^{1}$ Cinzia Dal Zotto, ${ }^{2}$ and Marco De Marco ${ }^{3}$ \\ ${ }^{1}$ FGES, Université Catholique de Lille, 59800 Lille, France. \\ ${ }^{2}$ Institute of Management, University of Neuchâtel, 2000 Neuchâtel, Switzerland \\ ${ }^{3}$ Department of Economics, University Uninettuno, 00186 Rome, Italy.
}

\begin{abstract}
The highly competitive and increasingly dynamic environment in which economic actors are currently operating requires more flexible and resilient organizations, even more so with the widespread of the COVID-19. With the emergence of the Industry 4.0 revolution, many sectors recognize the importance of innovative digital technologies for their activities and are reorganizing their traditional business model also in terms of smart working; others, are still in their infancy. This study explores the potential of smart working solutions to improve collaboration and efficiency in the work environment, by enabling at the same time an improved balance between private and working life. The paper uses secondary data as well as primary data obtained through interviews within the banking and insurance sectors in Italy and in Switzerland. By shedding light on benefits and drawbacks, research findings contribute to the discussion on smart working, which has emerged as a solution in pandemic emergencies but is becoming a new strategic paradigm for a sustainable and resilient organization of work in the future.
\end{abstract}

\section{Introduction}

Since the beginning of 2020, the overall world is threatened by the widespread of coronavirus (COVID-19) which began in Wuhan, China. The situation in Europe is also very dangerous for human health and it is having important impacts also at social and economic level. In February, Italy appeared as a pioneer case and got hit severely. However, soon the virus went around overcoming borders and reaping its victims in different countries with a heterogeneous trend. We are now in the middle of the second

\footnotetext{
* Corresponding author: eleonora.veglianti@univ-catholille.fr
} 
Coronavirus' wave and, while countries are starting to vaccinate its population, new and more dangerous variants are emerging.

This emergency has been going on for nearly a year now and is creating new challenges and opportunities in several fields. Within the same scenario, each country adopted different behaviors and measures to deal with this peculiar situation.

One of the most important and discussed topic regards the so-called smart working that allow people, depending on their job type, to continue working from home and thus helps minimizing transfers to reach offices or workplaces. Indeed, within the COVID-19 context, the main goal of smart working, as suggested by the World Health Organizations, is that of safeguarding and protecting the health of each individual and of our society as a whole.

During the peak of the COVID-19 pandemic, smart working is mainly considered as an answer to increase the protection from the virus; however, as time goes by, it results a way to reach higher flexibility and autonomy in the job system which becomes the further and long-term purpose.

In other words, the COVID-19 reopened the discussion on smart working and is representing now a compulsory test on a huge percentage of people who continues to work remotely from their homes during this emergency. A massive number of citizens in all countries has been obliged to work at home, starting from those who live and work in the areas most affected by the virus and, gradually followed by all the other individuals. This is the case, for instance, of Italy.

Other countries, especially the Northern European ones (i.e. Sweden), adopted a softer approach leaving people free to go around and keep their usual life and working habits, trusting the law-abiding behaviors of the citizens. In any case, smart working not only emerges as a powerful isolation measure, which many governments adopted to try to contain the diffusion of the pandemic. Its widespread application has further shown that in the digital era many individuals can work remotely without decreasing their productivity and thus reaching the required performance results.

For a long time, smart working has been a topic of discussion, dividing scientists, professionals, firms as well as politicians between supporters and those that consider smart working as a negative initiative. For instance, actors such as big consulting firms promote the advantages of applying smart working without many formalisms: they suggest their clients to base results on specific goals and, at the same time, they assist each employee by providing the needed technological tools and smart working kits to attain, even in emergency situations, the performance results. In addition, companies provide managers with various mechanisms to control the activities of their subordinates and better manage them also remotely.

This shows that some companies, thanks to their previous knowledge of digital working places (i.e., offering webinars, conference calls), are already prepared to deal with smart working or can more easily adapt to the emergency for the safety of their workforce without losing in terms of outcome. In the meantime, there are many other organizations that are not ready or have not enough resources to respond to smart working demands, especially in a short time frame such as an emergency.

We can think for instance of the small and medium enterprises (SME) or the numerous independent professionals, who in many European countries, such as Italy or Switzerland, represent the business fabric. However, even big and established actors such as banks or insurance companies are facing challenges. Thus, our study looks into these two sectors, and mainly for two reasons: (a) they are those with the highest potential for the application of remote working, and (b) they distinguish each other in terms of smart working adoption, with the banking sector having already widely implemented smart working, and the insurance sector still on a full presence working mode before the COVID-19 crisis. 
The aim of this study is thus to better understand a cross-section of smart working by analysing two sectors, insurance and banking, which represent a category of actors sufficiently equipped in terms of technology and thus potentially ready to quickly implement smart working in an emergency situation. We will do so by considering the universal features and challenges related to smart working together with the local and specific aspects influencing its implementation.

By comparing and analysing the above-mentioned sectors, this paper reflects about the potentiality of smart working to leverage technology to change organizational design, working processes as well as managerial mechanisms and create new opportunities for organizations, for instance by developing new forms of employees' autonomy, decreasing costs as well as having a positive impact on the environment.

Taking into consideration the particular situation due to the COVID-19 pandemic, our study seeks to answer the following main research question: What are the challenges and new opportunities of the intensification of smart working in times of a health crisis such as that of COVID-19?

To answer to this research question, we conduct a qualitative research. The present work suggests a novel way to study smart working, searching similarities and differences able to support a better understanding of this trend that promises enormous benefits and creates new challenges for companies, industries, institutions, and organizations in general.

Our paper is structured as follows: Section 2 explores the international literature; Section 3 defines the research goals and methodology; Section 4 presents the results and, finally, Section 5 concludes and discusses the results, analysing the limits of the paper and suggesting ideas for future research.

\section{Literature review}

\subsection{Overview}

In the last decades, the methods and the approaches through which work practices are accomplished have changed [1]. Successful organizations show new working configurations abandoning inappropriate and obsolete approaches [2] with the goal of promoting new organizational principles such as autonomy in the work settings [3], talent development, empowerment as well as the innovation diffusion [4].

With this paradigm shift, the value generation does not merely depend on the business model itself [5], but also and especially on how employees express their selves in shaping, perceiving and evolving the business model with their daily activities [6]. In line with this, an increasing number of companies/organizations are rethinking their business models in the light of smart working [7]. Specifically, smart working identifies a non-conventional organizational model that offers higher levels of flexibility and autonomy in the choice of working spaces, time and tools, thus providing all employees of an organization with the best working conditions to accomplish their tasks, attain objectives and achieve results while respecting their own life rhythm [8]. If this work-setting scenario is shaping the development of several industries, in the service sector it appears as a necessary measure to respond to the changing needs of customers and our societies as a whole.

Smart working is not a new concept in the international literature $[1,9,10,7$, $11,12,13,14]$ as it is already at least since the beginning of the XXI century that scholars debate about this work setting evolution which, pushed by technological progress and diffusion, creates new business configurations [2] and affects human resources, processes, space contexts [15] as well as corporate culture [16]. 
A number of scholars dealt with smart working focusing on the role of Information and Communication Technologies (ICT) in making work more portable and ubiquitous [13]. For example, we suggest three essential elements to define a smart working model [17]: (a) the use of ICT, (b) innovations in human resources management practices and in organizational models, (c) the reconfiguration of the workplace layout.

These three elements have a direct impact on the implementation of smart working. ICT solutions increase and support the sharing of documents, information and ideas among people working in the same organization/group [18]. Thus, each member of the organization can virtually and flexibly interact in real time, contributing to the implementation of smart working. The more technology diffuses, the higher not only the potential of applying smart working but also the change in the nature of tasks and work that further induces or enhances the need for a smarter way of working [19].

Such development faces management with physical and psycho-sociological distancing and the disruption of current managerial tools and methods [20]. Remote work further requires employees to gain new competences. As a consequence, new managerial actions and interventions (i.e., training courses or new incentive systems), new communications plans and processes are needed, which may lead to an overall reorganization as well as to a cultural change [21]. Other scholars highlight the need for strategies to adequately reconfigure the office layout (i.e. [15]).

In order to better understand the need for innovative HRM practices and new organizational models, we will now point out some of the advantages and disadvantages related to smart working.

\subsection{Advantages and Disadvantages of Smart Working}

When implementing smart working, one of the main difficulties for the organization is to get used to control performance and results by setting objectives and deadlines. Previously, with physical presence supervisors' control was more direct. Working from distance makes not only communication, but also management more complex [22-23]. Other scholars point out that the role of managers will increasingly base on trust, monitoring of performance linked to objectives and projects, as well as their capability to enforce deadlines [20].

One of the risks of smart working is related to work-life balance, and more specifically to the isolation that remote workers may encounter due to the lack or decrease of interaction and communication [23-24]. In order to minimize this risk and allow employees to flourish also while smart working, organizations can for instance construct a feeling of proximity by balancing virtual and face-to-face exchanges [20]. Specific, regular and clear communication arrangements are necessary also to follow up on the implementation of smart working, which could otherwise be quickly at risk. Remote workers tend to develop a very personal mode of organizing work and communicating, which may create problems in terms of data security but also work-life balance [25].

The role of managers in setting objectives, deadlines, and communication arrangements is thus key not only to attain company results but also to facilitate their teams in articulating the time dedicated to private and professional life [20]. Achieving work-life balance while doing smart working requires also skills that may not have been necessary to perform the same tasks in the office. For instance, some authors [26] highlight, the importance of task planning, goal setting and self-management. While others [24] add that "to ensure smart working during normal working hours, it is important to maintain focus, concentration and manage time well in order not to have to compensate for losses outside working hours and even during weekends".

The risk to work beyond the usual working hours may depend also on the fact that people working at a distance feel more responsible, which makes them usually also more productive [27]. 
Determining the link between smart working and productivity is however quite complicated, as there are a lot of variables to take into consideration. Being more autonomous and able to organize their own schedule makes smart workers perceive a sense of productivity [28]. A feeling of efficiency is also felt by a large proportion of smart workers in Portugal, having experienced smart working for the first time during the COVID-19 period [24]. Indeed, according to some literature, this kind of work would allow a better organization of private life, which could reduce absenteeism and increase efficiency [29].

However, the private settings of each worker in comment, such as family situation, occupation of the spouse, and the presence of children, need to be taken into account when seeking to determine and understand the efficiency of smart working [28]. We thus believe that the quality of communication and interactions with one's superior and colleagues, given also its contribution to maintain the team spirit, is a more important element in the quest for smart working productivity [23].

As smart working spreads so does the adoption of new organizational settings and the development of organizational culture [23]. Such changes are necessary in order to adapt to the de-spatialization that smart working engenders. They require a real investment in terms not only of organizational redesign but also of changing its mode of control. However, these costs can be balanced by the benefits emerging from an improved productivity, well-being, and smart workers' quality of life [24]. This holds true in particular in the case of occupations requiring greater concentration and creativity, which would see a real gain thanks to reduced interruptions and/or fragmentation of their working time [30].

Further research associates working remotely with status, for instance high-class professions in the service sectors [19]. Also, Mongey, Pilossoph, and Weinberg find that workers with "low-work-from-home" or "high-physical-proximity" jobs are less educated, have lower incomes and more likely live in a rented accommodation [31]. This highlights the fact that smart working may exacerbate the digital divide and inequality gap.

Considering smart working in the light of an emergency such as the COVID-19 pandemic, we can imagine that the above-mentioned advantages and disadvantages hold true but might be respectively reinforced or exacerbated. We thus formulate following propositions to guide our analysis when looking at smart working in the insurance and banking sectors from an empirical point of view:

a) Smart working changes the mode of controlling work and turns it to management by objectives, deadlines and results. Moreover, direct control is substituted by trust.

b) Smart working requires new ways of communicating, requiring specific and clear arrangements.

c) New communication arrangements while smart working help maintain team spirit, avoid isolation and thus achieve a better work-life balance.

d) Changed controlling mechanisms and communication modes lead to new organizational settings of which empowerment, teamwork and self-management are key elements.

e) Smart working implies the development of a new organizational culture, which becomes more collaborative, open and based on trust.

f) A smart working driven improvement of work-life balance leads to higher motivation and productivity of employees.

g) Given all the changes that smart working requires, the supportive roles of managers/supervisors and the HRM department are determinant for its successful implementation. 


\section{Research Methodology}

Smart working has become a crucial topic in this pandemic period and raises several questions regarding the management of the labor force. Moreover, it shows the state of the art of digital development within the frame of single companies, industries, institutions as well as countries as a whole.

In this peculiar context, as already mentioned, it is important to note that not all types of jobs can be done from home. Thus, in this paper we specifically refer to smart working only with reference to those categories of jobs that do not require a compulsory physical presence and can be done also from home.

In order to explore and understand a complex issue such as smart working, the present paper follows a qualitative and exploratory research approach, which is characterized by the potential for revealing complexity by its richness and holism [32]. As the relevant literature suggests, the use of qualitative research methods is appropriate to investigate "a contemporary phenomenon within its real-life context; when the boundaries between phenomenon and context are not clearly evident; and in which multiple sources of evidence are used" [33].

As our aim is to closely study data within a specific context, we decided to conduct a sector-specific analysis, based on the triangulation of literature review, secondary data and expert interviews conducted during the time of the COVID-19 pandemic. Interviews with a convenience sample of key informants were semi-structured and conducted, due to the pandemic restrictions, either by phone or email between February 2020 and January 2021.

Our sample consists in twelve interviewees working within six different organizations in the banking and insurance sectors in two neighboring countries, Italy and Switzerland. These organizations are representative of the sectors under investigation in both countries as they are part of groups operating nationwide. According to several academics, there is no optimal sample size but a number between six and twelve informants [34-35] is suggested.

The experts interviewed were either HR managers or senior executives. Following are some of the questions that we posed: How can you define smart working? What are the advantages of smart working for your organization? What are the benefits for your employees? What are the disadvantages of smart working for your organization? What are the drawbacks for your employees?

Then, secondary data were collected by analyzing company reports, news and press releases as well as further internal documents that were made available by the companies.

The analysis looks both at the theoretical and empirical spheres of the smart working phenomenon [36]. In line with the relevant literature and with the purpose of this paper, we adopt a descriptive approach to analyze the phenomenon in a narrative form [37]. This allows us to design an examination of data conducted within the context of its use, that is within the situation in which the activity takes place [33].

\section{Emerging Results}

\subsection{Smart working in the Banking sector - Italy}

From our analysis of the banking sector in Italy, smart working appears as a needed step in the organization of work and in its overall setting to better answer to clients requests as well as to offer a more diversified service. Thus, the COVID-19 pandemic has been acting as an accelerator of the digital transformation of the banking services and of the development of a smarter approach in the working model. The bank sector in Italy started the path of going 
smarter before the COVID-19 outbreak, which is just pushing this transformation further representing both an opportunity and a challenge.

The investigation shows that at the bank headquarters in February 2020, when the COVID-19 pandemic exploded in Italy, highlighted that the number of online services increased, and $85-90 \%$ of the services that could be managed remotely were transformed into smart working activities. Certainly, the COVID-19 improved the Home Banking service. However, in the last years, the banking sector has already been preparing the ground for this development.

For instance, several training courses started to better explain to employees, at different levels, the new technological scenario as well as all the processes and steps required to improve their knowledge of an online organizational setting. The smart working direction was thus already set, the pandemic has just enhanced an already existent online mindset toward a new business model. The COVID-19 outbreak has not implied layoffs yet, but rather a change in the hiring specifications which now include skills and capabilities linked to the technology that smart working requires.

Within this context, the importance of taking into account the local features of a bank emerged. The office location is for instance a critical element that influences smart working decisions and implementation. In some places, a full digital and smart working-driven banking model is probably not the right option as some local people such as the elderly might not be able to use digital services and/or do not feel safe in using them, thus preferring the traditional bank business model.

We can thus say that smart working is considered the future business model for the banking sector. However, the performance of a full digital bank can be clearly impacted by the client target. In this respect, the COVID-19 outbreak is representing a good opportunity to test the functioning and suitability of smart working. Nevertheless, to continue to adequately assist clients a partial lockdown was organized by the bank meaning that smart working is not concerning all the staff of the bank at the same time.

In terms of advantages and disadvantages, on the employees' side, we found that the staff likes smart working as it allows to be closer to the family and reach a better work-life balance. However, employees refer to be missing the human face-to-face contact. On the bank side, several costs such as office renting can be avoided. However, the main drawback appears to be the possible loss of an important part of clients which are not able to use online services. In Italy, the latter can represent a crucial slide of the population.

It is clear that the banking sector is changing its business model and that COVID-19 is just accelerating this reorganization. This trend is confirmed by the meetings that several trade unions are having to discuss the agreements' modifications due to the smart working implementation. If on one hand, smart working presents several benefits both for the employees and the bank in terms of improved work-life balance and savings, on the other hand its successful implementation requires the creation of a clear policy and specific features to ensure equal treatment and avoid confusion in the short and in the long term.

\subsection{Smart working in the Banking sector - Switzerland}

Smart working seems to be very appealing to the banking sector in Switzerland. In the case that we analyzed the bank is planning to have up to a third of its employees able to work remotely over time. At the height of the COVID-19 epidemic, $80 \%$ of employees have been working in home offices.

The banking group however considers bringing back some employees as part of a phased approach by region, as managers are well aware that remote working may engender isolation and create communication as well as control related problems. The bank believes that an appropriate split between home office and office presence will lead to a reduced 
need for real estate, and thus to savings in the long term. It is still unclear which functions will return to the office.

The back office as well as the advice to wealthy clients are most likely to continue working remotely. In contrast, employees working on trading activities are "easier" to conduct on-site, just like those who have to prepare for an Initial Public offering (IPO) or whose activity requires physical presence such as change projects and or outward-looking activities. Smart working can however be reestablished at once, if the sanitary situation requires it.

The implementation of smart working started well before the pandemic. Among the main drivers of smart working the bank highlights the hyper-connectivity and hyperindividualization characterizing customer requests and relations, as well as advantages such as a more motivated and flexible workforce, the possibility to access specialized skills from remote as well as cost optimization issues.

Employees seem also to gain in balance between private and professional life, flexibility in organizing their work and reduced business travel (time saving). To ensure a successful implementation of smart working, the bank is also considering that potential disadvantages may appear. On one hand, at company level, difficulties in the development and maintenance of a collective identity, a lower quality of knowledge and information exchange, as well as data security problems may emerge. On the other hand, employees may face the risk of isolation or a limited access to certain features. For instance, traders moving to smart working may miss the frenzy of their daily environment in the old world.

In order to prevent this problem, the bank is trying to recreate the experience of a trading room by applying virtual immersive reality tools. Such measure aims at keeping up the motivation of certain employees and thus improving their productivity when working from home.

Our analysis reveals that the banking sector, also in Switzerland, is pushing forward the digital transformation of their business and the Covid-19 emergence acts as an accelerating factor for an already ongoing process which gains this way in acceptance and efficiency.

\subsection{Smart working in the Insurance sector - Italy}

The insurance sector has been highly impacted by the COVID-19 especially both in terms of performance (i.e. less insurance policies as people do not travel) and in terms of working organization. The remote working mode imposed by the pandemic outbreak is not very much in line with the insurance business and, indeed, it has not been considered as a needed step until now.

There are several reasons why the insurance sector is not ready to have its staff work from remote. For instance, the face-to face contact is considered as crucial to better fit the client's requests. Even though the business includes online services as well as services managed by phone, it still appears to be far from the development and implementation of smart working. In addition, most of the people works as independent consultant without strict time constrains.

During the pandemic, the physical presence has been continuing even during the lockdown with a rotation-based work organization (50\% presence) in order to ensure the assistance to all clients. Thus, the insurance sector activated only a partial lockdown. In other words, mostly due to the business constraints, the sector was not prepared for smart working and so it could not fully test it during the pandemic.

Our analysis reveals that a part of coworkers in the Italian insurance sector do not have an employee agreement but are rather employed as independent consultants and thus already work - even before COVID-19 - with a different setting and time management. This is the reason why the individuals that we interviewed are not significatively impacted 
by the new organizational setting imposed by the pandemic, as they already have a consultant "mindset" which differs from that of employees in various elements such as for instance time constraints. On the one hand, the main advantage of smart working appears to be safety which is predominately linked to the pandemic emergency. On the other hand, the most relevant disadvantage is the loss of face-to-face contact.

Even if the COVID-19 is obliging the insurance sector to deal with a partial smart working, the latter does not represent a proper way to serve clients. Hence, the insurance sector currently prefers not to change its traditional business model and the pandemic is not accelerating the implementation of smart working nor a more general digital transformation.

As the pandemic situation will improve/end, the sector wants to fully reestablish its traditional working approach. In conclusion, in this case, smart working is not found as an alternative but as a temporary way for organizing work due to the COVID-19. No main changes have been introduced related to the controlling of work nor are specific smart working-related policies foreseen. However, following the digital transformation that the overall society is facing, the chances that smart working will be implemented also in the insurance sector could increase in the next future.

\subsection{Smart working in the Insurance sector - Switzerland}

In Switzerland the situation is a bit different. The insurance sector has a labor force divided into 3 main parts: the employees dedicated to sales who mostly and naturally work out of the office, the employees dedicated to risk management and those who work on new product development.

The sector was not particularly ready for implementing the lockdown-driven distance working as the usual working mode was the presential one. However, before the pandemic, among the employees with managerial responsibility - thus excluding the sales workforce $24 \%$ already worked from home once a month and $19 \%$ about once a week. With the pandemic the sector immediately changed to a full smart working mode. Clearly, the insurance companies had the technological infrastructure to allow this and no major adaptation was needed to make this transition.

In terms of advantages and disadvantages of smart working, our analysis further highlights that the large majority of managers do not perceive problems in supervising their teams remotely, $4 \%$ of them even state that they can better manage in smart working mode, while $13 \%$ of managers refer to have faced some problems.

The survey that the companies included in our study have conducted among about 225 of their managers identifies that more than half of those managers noted a greater implication as well as a higher individual productivity of their subordinate. More than $40 \%$ of managers found also a positive impact of smart working on collaboration and communication. On the side of disadvantages, $20 \%$ declared a negative impact on the progress of ongoing projects, $15 \%$ faced communication problems and a diminished productivity of the employees.

As we can see, the insurance companies in our sample were positively surprised by the effects of smart working and are seriously thinking to maintain a certain degree of flexibility of working time and place for their employees after the end of the pandemic emergency. When asked about the possibility to prolong smart working $50 \%$ of the very same managers that have been surveyed forecast that there will be between a slight and a strong improvement of employees' engagement and productivity. About $30 \%$ expect an improved communication, too. The more skeptical managers say that there will be a negligeable impact or a slight degradation in collaboration, communication and in the advancement of projects. 
Finally, $80 \%$ of managers within the companies that we have analyzed declare that they would be ready to do smart working for one or two days in a week without having any negative impact on their supervising job. Even though about $60 \%$ of managers think that going back to a full presential mode of working would not be adequate for the vast majority of employees, who got used to higher flexibility and an improved work-life balance, about $83 \%$ of those managers estimate that smart working should not be stretched beyond 2 days a week.

All in all, we can say that, in order to properly meet employees' needs and well as clients' and overall business needs, the insurance sector in Switzerland would be ready to implement a hybrid mode of working which regularly include one or two days a week of smart working. The companies in the sample further stated that a formal company policy concerning smart working should be developed and implemented in order to avoid misunderstandings and/or unfair treatments.

In the table below we have summarized the main features related to smart working within the banking and insurance sectors in Italy and Switzerland as they emerged from our investigation.

Table 1: Main features related to smart working in the banking and insurance sectors - Italy and Switzerland

\begin{tabular}{|c|c|c|c|c|}
\hline \multirow{2}{*}{$\begin{array}{l}\text { Main } \\
\text { characteristics }\end{array}$} & \multicolumn{2}{|c|}{ Italy } & \multicolumn{2}{|c|}{ Switzerland } \\
\hline & $\begin{array}{l}\text { Banking } \\
\text { sector }\end{array}$ & $\begin{array}{l}\text { Insurance } \\
\text { sector }\end{array}$ & Banking sector & $\begin{array}{l}\text { Insurance } \\
\text { sector }\end{array}$ \\
\hline $\begin{array}{l}\text { Readiness to smart } \\
\text { working }\end{array}$ & high & low & high & $\begin{array}{l}\text { low, if non } \\
\text { existent }\end{array}$ \\
\hline $\begin{array}{l}\text { Use of smart } \\
\text { working before } \\
\text { Covid-19 }\end{array}$ & yes & no & yes & no \\
\hline $\begin{array}{l}\text { Smart working } \\
\text { appropriate for } \\
\text { clients }\end{array}$ & $\begin{array}{l}\text { depends } \\
\text { on client's } \\
\text { ability to } \\
\text { use the } \\
\text { online } \\
\text { services }\end{array}$ & $\begin{array}{l}\text { not } \\
\text { appropriate }\end{array}$ & $\begin{array}{l}\text { depends on the } \\
\text { service } \\
\text { delivered }\end{array}$ & $\begin{array}{l}\text { not very } \\
\text { appropriate }\end{array}$ \\
\hline $\begin{array}{l}\text { Advantages of } \\
\text { smart working }\end{array}$ & $\begin{array}{l}\text { savings } \\
\text { (i.e. } \\
\text { renting) } \\
\text { better } \\
\text { work-life } \\
\text { balance } \\
\text { for } \\
\text { employees }\end{array}$ & safety & $\begin{array}{l}\text { savings, } \\
\text { motivation, } \\
\text { flexibility, better } \\
\text { work-life } \\
\text { balance, less } \\
\text { business travel }\end{array}$ & $\begin{array}{l}\text { better work-life } \\
\text { balance, } \\
\text { productivity, } \\
\text { communication }\end{array}$ \\
\hline $\begin{array}{l}\text { Disadvantages of } \\
\text { smart working }\end{array}$ & $\begin{array}{l}\text { loss of } \\
\text { face-to- } \\
\text { face } \\
\text { contact for } \\
\text { employees }\end{array}$ & $\begin{array}{l}\text { loss of } \\
\text { face-to- } \\
\text { face } \\
\text { contact for } \\
\text { employees } \\
\text { and } \\
\text { companies }\end{array}$ & $\begin{array}{l}\text { isolation, } \\
\text { communication, } \\
\text { work control } \\
\text { issues }\end{array}$ & $\begin{array}{l}\text { collaboration, } \\
\text { progress of } \\
\text { project work }\end{array}$ \\
\hline $\begin{array}{l}\text { After COVID-19, } \\
\text { smart working is } \\
\text { going to affect the } \\
\text { business model }\end{array}$ & yes & no & yes & no \\
\hline
\end{tabular}




\section{Conclusions and discussion}

The COVID-19 pandemic clearly highlights a breaking point concerning smart working in particular, and the digital transformation of firms more in general. On one side, we could observe those economic actors that, having already adopted smart working beforehand, demonstrated to be culturally and technologically ready to switch to a remote mode of work at the point of the emergency as for instance the banking sector.

Such actors were able to confirm their achievements and their position in the market of reference. On the other side, there are other operators that, lagging behind in terms of technology adoption, are not able to answer well to the digitalization of their labor force. The latter is more the case of the insurance sector.

As our analysis highlights, the acceleration of smart working in the current emergency situation is emphasizing the criticality of the digital transformation path of organizations and asking for innovative solutions. Governments and companies need to put this discussion on their agendas and develop appropriate measures and interventions to improve the intangible infrastructures (i.e. the network coverage), people's skills and capabilities (from a basic to a more advanced knowledge) as well as the cultural attitudes (i.e. the planning of work and the goals).

In other terms, we can consider the present emergency crisis as both an opportunity and a challenge to test the digital maturity of many sectors/industries/organizations and, consequently, an important experiment that may lead to reconceive the business models of many public and private players.

As our results suggest, smart working represents a new way of controlling work which requires specific and clear arrangements in terms of communication and trust between the single employees and their supervisors. Moreover, in the two industry sectors analyzed in this paper, smart working appears as a key element for improving employees' work-life balance leading to higher motivation and productivity compared to traditional working environments.

Many organizations started experimenting smart working for the first time during the COVID-19 pandemic. Bound to introduce it for safety reasons, they were not ready to manage it. Thus, difficulties and drawbacks emerged such as the need to fix clear objectives and manage by results, to make clear communication arrangements so to maintain team spirit and avoid isolation, the risk of affecting careers advancements due to the lack of faceto-face contact, just to name but a few. Certainly, advantages and disadvantages of smart working require further and more in-depth discussions to ensure a successful and appropriate implementation of smart working.

However, the unique and widespread smart working experiment that we have been and are still living during the COVID -19 pandemic is enhancing the role and importance of digital transformation, which is not only leading to major changes in our private and professional lives but appears to be a way to organize future work settings in a sustainable and resilient way. By highlighting the need for a more holistic approach toward issues of business health and overall performance, the current emergency is thus improving the organizations' ability to respond and adapt to incremental change and disruptions.

This paper does not aim at delivering practical indications in terms of best practices for smart working solutions. Rather it was designed to explore a phenomenon that emerged worldwide as a general solution to introduce within private and public organizations due to the pandemic situation and that is going to be a valid alternative for the future organization of work.

The outcome has implications for future scholarly research and for practitioners. Our research sheds light on the state of the art of smart working and on its peculiarities within the insurance and banking sectors as well as in the countries of investigation. It delivers 
important hints for practitioners who want to implement smart working in Italy and in Switzerland in general, and specifically in the banking and insurance fields.

This paper can thus be very useful for those entities aiming at investing in the digital transformation of their organizations by pushing a sustainable reorganization of the work setting. Indeed, they should take into consideration that each sector and country need tailored solutions.

Future scientific studies could approach the topic through a multi-level analysis, presenting for instance a comparison with other countries (i.e. the ones that have a softer approach vs. those that have a more rigid approach toward smart working), including additional sectors, or looking at the differences between developed and underdeveloped economies. Moreover, a mix of qualitative and quantitative methods could be fruitfully applied.

\section{References}

[1] G. Hamel, What Matters Now: How to Win in a World of Relentless Change, Ferocious Competition, and Unstoppable Innovation, (Jossey-Bass, San Francisco:USA, 2012)

[2] J. Birkinshaw, G. Hamel, M. Mol, Management Innovation, J. Acad. Manag. Rev., 33(4), 825-845 (2008)

[3] P.M. Leonardi, D.E. Balley, Transformational Technologies and the Creation of New Work Practices: Making Implicit Knowledge Explicit in Task-Based Offshoring, JSTOR MIS Quart., 32(2), 411-436 (2008)

[4] G. Hamel, B. Breen, The Future of Management (Harvard Business School Press, Boston, MA, 2007)

[5] R. Gunther McGrath, The End of Competitive Advantage: How to Keep Your Strategy Moving as Fast as Your Business (Harvard Business Review Press, Boston, MA, 2013)

[6] S.L. Brown, K.M. Eisenhardt, Competing on the Edge (Harvard Business School Press, Boston, MA, 1998)

[7] Plantronics, Smarter Working, www.plantronics.com/us/solutions/smarter-working (2014)

[8] D. De Masi, Smart Working. La rivoluzione del lavoro intelligente, Marsilio (Eds.) (Venezia: Italy, 2020)

[9] R. Bonanni, M. Danza, Smart working tra crisi e innovazione, Bertoni (Eds.) (Marsciano: Italy, 2020)

[10] T. Botteri, G. Cremonesi, Smart working \& smart workers, Franco Angeli (Eds.) (Milano: Italy, 2016)

[11]A. Lake, Smart Flexibility: Moving Smart and Flexible Working from Theory to Practice (Routledge, CRC Press, London: UK, 2013)

[12] A.M. McEwan, Smart Working: Creating the Next Wave (Routledge, CRC Press, London: UK, 2013)

[13] Y. Yoo, O. Henfridsson, K. Lyytinen, The New Organizing Logic of Digital Innovation: An Agenda for Information Systems Research, J. INFORMS, 21(4), 724735 (2010)

[14]M.K. Ahuja, K.M. Chudoba, C.J. Kacmar, D.H. McKnight, J.F. George, IT Road Warriors: Balancing Work-Family Conflict, Job Autonomy, and Work Overload to Mitigate Turnover Intentions, JSTOR MIS Quart., 31(1), 1-17 (2007)

[15] L. Smith, M. Ucci, A. Marmot, R. Spinney, M. Laskowski, A. Sawyer, M. Konstantatou, M. Hamer, G. Ambler, J. Wardle, A. Fisher Active buildings: modelling physical activity and movement in office buildings, BMJ Open 3 (11), 1-15 (2013) 
[16]L. Joo-Hyoung, K. Sun-Bae, A Desirable Corporate Culture under Smart Work Environment, J. Dig. Conv., 10(11), 93-102 (2012)

[17] J. Mann, Transform the Workplace with Focus on Bricks, Behaviors and Bits (Gartner, Stamford: USA, 2012)

[18] K.Chudoba, E. Wynn, M. Lu, M. B. Watson-Manheim How virtual are we? Measuring virtuality in a global organization, J. Inf. Syst., 15(4), 279-306 (2005)

[19] B. Vilhemson, E. Thulin, What did we do when the Internet wasn't around? Variation in free-time activities among three young-adult cohorts from 1990/1991, 2000/2001, and 2010/2011, SAGE J., 31(1),77-96 (2017)

[20]C. Ruiller, M. Dumas, F. Chédotel How to maintain the feeling of proximity at a distance? The case of teams dispersed by teleworking, J. RIMHE, 27(3), 3-28 (2017)

[21]E. Cameron, M. Green Making Sense of Change Management: A Complete Guide to the Models Tools and Techniques of Organisational Change (Kogan Page, London: UK, 2012)

[22]M. Vartiainen, M. Hakonen, S. Koivisto, P. Mannonen, M.P. Nieminen, V. Ruohomäki, A. Vartola, Distributed and Mobile Work: Places, People and Technology. (Otatieto, Helsinki, 2007) 1-177

[23] A. Aguilera, V. Lethiais, A. Rallet, L. Proulhac Le télétravail, un objet sans désir? (Armand Colin, Paris: France, 2016) 245-266

[24]F. Tavares, E. Santos, A. Diogo, V. Ratten, Teleworking in Portuguese communities during the COVID-19 Pandemic. J. Entrep. Communit., (2020) (in press)

[25] M. Dumas, C. Ruiller, Le télétravail : les risques d'un outil de gestion des frontières entre vie personnelle et vie professionnelle? J. Manag. Aven., 74(8) ,71-95 (2014)

[26] E. Vayre, C. Delfosse Vayre, Les enjeux psychosociaux du télétravail: comment accompagner les organisations? J. psychol., 367(5), 22-26 (2019)

[27] Telecowork, Télétravail: 5 bonnes raisons de le proposer à vos collaborateurs, https://www.telecowork.com/5-raisons-teletravail (2017)

[28]N. Donnelly, S.B. Proctor-Thomson, Disrupted work: home-based teleworking (HbTW) in the aftermath of a natural disaster. J. New Techn., Work and Employm., 30(1), 47-61 (2015)

[29] K.A. Basile, T.A. Beauregard, Boundary Management: Getting the Work-Home Balance Right. Agile Working and Well-Being in the Digital Age (Springer, Switzerland, 2020) 35-46

[30] J. Vacherand-Revel, M. Ianeva, J. Guiboudenche, J.F. Carlotti, The practices of the pendulum telework managers: reconfiguration relational ecosystems and activities, J. Psychologie du travail et des organisations, 22(1), 54-73 (2015)

[31] S. Mongey, L. Pilossoph, A. Weinberg, Which Workers Bear the Burden of Social Distancing Policies? Becker Friedman Institute white paper (2020)

[32] M.B. Miles, A.M. Huberman, J. Saldana Qualitative Data Analysis: A methods Sourcebook (SAGE Beverly Hills, California, 2014)

[33] R.K. Yin, Case Study Research: Design and Methods (SAGE Beverly Hills, California, 1984)

[34]P. Eriksson, A. Kovalainen Qualitative methods in business research (SAGE Beverly Hills, California, 2008)

[35] J.F. Gubrium, J.A. Holstein A.B. Marvasti., K.D. McKineey The Sage Handbook of Interview Research: The Complexity of the Craft (SAGE Beverly Hills, California, 2012)

[36] A. Bryman, E. Bell, Business research methods (Oxford University Press, Oxford, 2011)

[37] J. McDonough, S. McDonough, Research Methods for English Language Teachers (Arnold, London, 1997) 